СЕЛЕЦЬКИЙ В.С., к.т.н., провідний інженер (ВП “Львівське відділення” філії “ГІОЦ” ПАТ "Укрзалізниця")

\title{
Технологія розробки інформаційного забезпечення для моделей складних об'сктів
}

У розробиі інформаційного забезпечення для моделей складних об’єктів, які побудовані за допомогою розиирених мереж Петрі з використовуванням методу декомпозицій, запропоновано алгоритм створення структурованих XML файлів вхідних даних для мереж-сценаріїв (1-й рівень мереж), функиій-мереж (2-й рівень мереж), підфункиій-мереж (3-й рівень мереж) і т.д. для забезпечення достовірності обробки даних на кожному рівні.

Ключові слова: модель, метод декомпозиції, розиирена мережа Петрі, XML файли вхідних даних.

\begin{abstract}
Постановка проблеми
В інформаційному забезпеченні [1], яке розроблене для складних автоматизованих систем на підставі математичного апарату мереж Петрі, запропоновано для достовірної обробки даних використовувати вхідні дані, які подаються у форматі XML, замість вхідних даних у форматі RTM, які використовували раніше.

У статті [2] побудовано XML файли вхідних даних для примітивних моделей, які містять елементи розширеної мережі Петрі, i запропоновано в інформаційному забезпеченні, яке розробляється для автоматизованих систем різних складних об'єктів, на підставі примітивних моделей для достовірної обробки даних використовувати файли вхідних даних у форматі XML.
\end{abstract}

Для побудови моделі підсистеми розформовування поїздів на сортувальній станції запропоновано метод декомпозиції [3-7]. При застосовуванні методу декомпозиції модель будується за ієрархічною системою 3 декількох рівнів мереж. На 1-му рівні розміщуються мережі-сценарії, на 2-му рівні розміщуються функції-мережі, на 3-му рівні розміщуються підфункції-мережі і т.д.

У [8] введені нові популяції мереж Петрі (МП): МП в одновимірному просторі $\left(M \Pi \in \boldsymbol{R}^{\boldsymbol{l}}\right) ;$ МП у двовимірному просторі (MП $\left.\in \boldsymbol{R}^{2}\right)$; МП у тривимірному просторі $\left(M \Pi \in \boldsymbol{R}^{3}\right) . \quad$ При побудові $M \Pi \in \boldsymbol{R}^{3}$ використовувався метод декомпозицій i було запропоновано таблицю досягнень станів перебування технологічних процесів моделі, яка побудована за допомогою $M \Pi \in \boldsymbol{R}^{3}$, розбивати на динамічні таблиці відповідних мереж-сценаріїв та функцій-мереж даної моделі.

() В.С. Селецький, 2016
При розробці інформаційного забезпечення для моделей складних об'єктів, які побудовані за допомогою розширених мереж Петрі з використанням методу декомпозицій, виникає потреба у створенні структурованих XML файлів вхідних даних для мережсценаріїв, функцій-мереж, підфункцій-мереж і т. д.

\section{Постановка задачі \\ Для опису звичайних мереж Петрі і розширених мереж Петрі мовою XML у статтях $[1,2]$ : \\ - введені назви елементів звичайної і розширеної мереж Петрі в XML: простої позиції, простого переходу, вхідної дуги, вихідної дуги, інгібіторної дуги, інгібіторної дуги $n$-го порядку, позиції $n$-го рівня, позиції з фіксованим часом затримання фішок, позиції $n$-го рівня 3 фіксованим часом затримання фішок, простої предикатної позиції і предикатної позиції $n$-го рівня i їх позначення в XML: номер позиції, номер переходу, вихід дуги з позиції, вхід дуги в перехід, вихід дуги з переходу, вхід дуги в позицію, вага вхідної дуги, вага вихідної дуги, вага інгібіторної дуги, номер рівня в позиції $n$-го рівня, час затримування фішки;}

- для достовірної обробки даних розроблені файли вхідних даних у форматі XML як для моделей, які побудовані за допомогою звичайних мереж Петрі, так і для примітивних моделей, які містять елементи розширеної мережі Петрі.

Таким чином, для моделей складних об'єктів, які побудовані за допомогою розширених мереж Петрі 3 використанням методу декомпозицій, потрібно:

- ввести позначення величин в XML для мережсценаріїв, функцій-мереж, підфункцій-мереж і т.д.;

- розробити структуровані XML файли вхідних даних для мереж-сценаріїв, функцій-мереж, підфункцій-мереж і т. д. 


\section{Рішення проблеми}

Із застосовуванням методу декомпозиції модель складних об'єктів (див. рис. 1) побудована за ієрархічною структурою з трьох рівнів мереж:

- на 1-му рівні розміщено мережу-сценарій $S_{1}$, яка моделює автоматизовану систему керування складними об' єктами (АСКСО);

- на 2-му рівні розміщено функцію-мережу $F_{1}$, яка моделює сервер, на якому обробляються повідомлення, які передаються 31 автоматизованих робочих місць $\left(A P M_{i}\right.$, де $\left.1 \leq i \leq l\right)$;

- на 3-му рівні розміщено:

- підфункції-мережі $s F_{i}, \quad$ де $1 \leq i \leq l, \quad$ які моделюють $A P M_{i}$, де $1 \leq i \leq l$. В $A P M_{i}$, де $1 \leq i \leq l$, підготовляються повідомлення виду “ $l$ ”, які передаються на сервер $F_{1}$ і відповідно $l^{\prime}$ інформаційних довідок запрошуються 3 сервера $F_{1}$;
- підфункції-мережі $s F_{J}$, де $1 \leq j \leq m$, які моделюють $A P M_{j}$, де $1 \leq j \leq m$. В $A P M_{j}$, де $1 \leq j \leq m$, підготовляються повідомлення виду “2”, які передаються в АСКСО - $S_{1}$, і відповідно $m$ інформаційних довідок запрошуються з АСКСО - $S_{1}$.

В $A P M_{i}$, де $1 \leq i \leq l$ (підфункція-мережа $s F_{i}$ ):

- позиція $n_{1}$-го рівня 3 фіксованим часом затримування $P_{1 i}^{2}$, де $1 \leq i \leq l$, моделює підготовку (редагування) повідомлень виду “ 1 ”;

- позиція $n_{1}$-го рівня 3 фіксованим часом затримування $P_{2 i}^{2}$, де $1 \leq i \leq l$, моделює формування повідомлення у форматі XML (у форматі RTM) обробник повідомлень;

- перехід $t_{1 i}^{2}$ моделює надходження введеного (відредагованого) повідомлення в обробник повідомлень;

- перехід $t_{2 i}^{2}$ моделює закінчення обробки повідомлення і передачу його в сервер $F_{1}$.

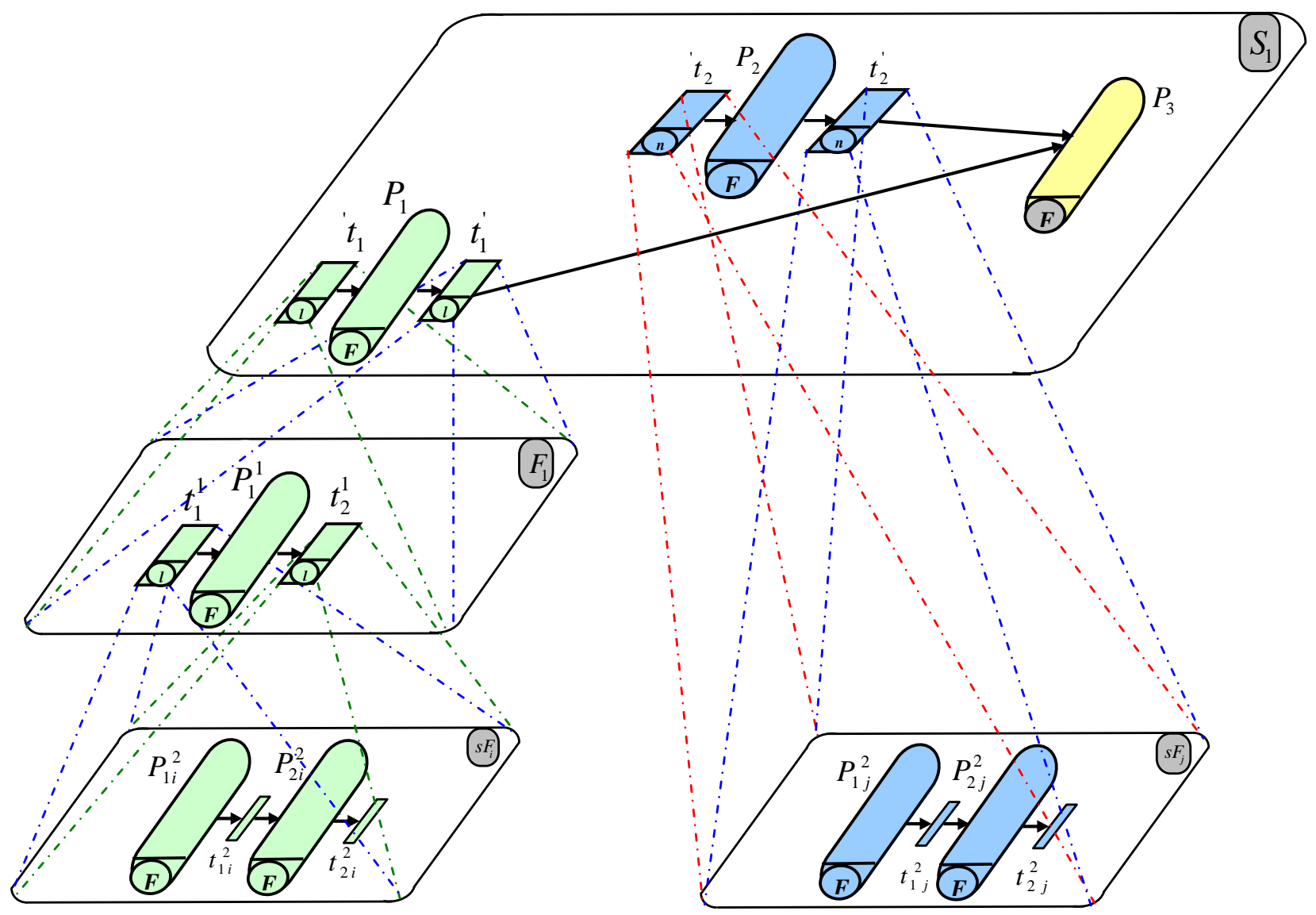

Рис.1. Модель складних об'єктів 
За аналогією в $A P M_{j}$, де $1 \leq j \leq m$ (підфункціямережа $\left.s F_{j}\right)$ :

- позиція $n_{2}$-го рівня 3 фіксованим часом затримування $P_{1 j}^{2}$, де $1 \leq j \leq m$, моделює підготовку (редагування) повідомлень виду “2”;

- позиція $n_{2}$-го рівня 3 фіксованим часом затримування $P_{2 j}^{2}, \quad$ де $\quad 1 \leq j \leq m, \quad$ моделює формування повідомлення у форматі XML (у форматі RTM) - обробник повідомлень;

- перехід $t_{1 j}^{2}$ моделює надходження введеного (відредагованого) повідомлення в обробник повідомлень;

- перехід $t_{2 j}^{2}$ моделює закінчення обробки повідомлення і передачу його в АСКСО - $S_{1}$.

\section{У сервері (функиія-мережа $\left.F_{1}\right)$ :}

- обробник повідомлень, які надходять $3 A P M_{i}$, де $1 \leq i \leq l$, змодельовано за допомогою позиції $r$-го рівня з фіксованим часом затримування $P_{1}^{1}$;

- перехід $t_{1}^{1}$ моделює надходження повідомлень в обробник;

- перехід $t_{2}^{1}$ моделює закінчення обробки повідомлення і передачу його в АСКСО - $S_{1}$.

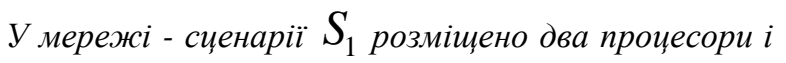
банк даних.

У прочесорі 1:

- за допомогою позиції $z_{1}$-го рівня $з$ фіксованим часом затримування $P_{1}$ змодельовано обробник повідомлень, які надходять із сервера $F_{1}$;

- перехід ' $t_{1}$ моделює надходження повідомлень в обробник;

- перехід $t_{1}^{\prime}$ моделює закінчення обробки повідомлення в обробнику і надходження інформації в банк даних (записування нормативно-довідкової інформації (НДІ) по моделях).

У прочесорі 2:

- за допомогою позиції $z_{2}$-го рівня $з$ фіксованим часом затримування $P_{2}$ змодельовано обробник повідомлень, які надходять $3 A P M_{j}$, де $1 \leq j \leq m$;

- перехід ' $t_{2}$ моделює надходження повідомлень в обробник;
- перехід $t_{2}^{\prime}$ моделює закінчення обробки повідомлення в обробнику і надходження інформації в банк даних (записування НДІ по моделях).

Банк даних змодельвано за допомогою позиції $P_{3} n$-го рівня.

Як $з A P M_{i}$, де $1 \leq i \leq l$, так і з $A P M_{j}$, де $1 \leq j \leq m$, підготовлену інформацію (повідомлення) даних пропонується передавати як у сервер, так і в $\mathrm{ACKCO} \mathrm{для} \mathrm{достовірної} \mathrm{обробки} \mathrm{у} \mathrm{форматі} \mathrm{XML,} \mathrm{a}$ запити різних довідок в $A P M_{i}$ або в $A P M_{j}$ пропонується передавати у форматі RTM. По-перше, інформація довідок у форматі RTM є більш зрозумілою для будь-якого кола користувачів. По-друге, швидкість надходження інформації у форматі RTM набагато більша, ніж швидкість надходження інформації у форматі XML, так як розмірність RTM файлів менша, ніж розмірність XML файлів. На рис. 2 наведено блоксхему передавання i приймання інформації для побудованої моделі складних об'єктів.

Підготовлені повідомлення в $A P M_{i}$, де $1 \leq i \leq l$, або в $A P M_{j}$, де $1 \leq j \leq m$, які передаються у форматі XML у сервер або в ACKCO, для забезпечення достовірної обробки даних і отримання позитивних результатів повинні оброблятися XSD схемами, так як XSD схеми забезпечують строгість правил побудови структури XML файлів.

Для наведеної моделі складних об'єктів побудова узагальненої динамічної таблиці функціонування технологічних процесів розбивається на таку послідовність побудови динамічних таблиць:

- динамічні таблиці функціонування технологічних процесів для $A P M_{i}$, де $1 \leq i \leq l$, і для $A P M_{j}$, де $1 \leq j \leq m$;

- динамічна таблиця функціонування технологічних процесів сервера;

- динамічна таблиця

функціонування технологічних процесів АСКСО.

При розробці структурованих XML файлів вхідних даних для АСКСО введені такі позначення:

1) $\boldsymbol{M} \_S$ - мережа-сценарій;

2) $\boldsymbol{M} \_\boldsymbol{F}-$ функція-мережа;

3) $\quad \boldsymbol{M} \_\boldsymbol{S u b}-\boldsymbol{F}-$ підфункція-мережа.

XML файли для $\boldsymbol{M} \_\boldsymbol{S}$ - мережі-сценарію, $\boldsymbol{M} \boldsymbol{F}$ функцій-мереж i $\boldsymbol{M} \_\boldsymbol{S u b}-\boldsymbol{F}$ - підфункцій-мереж повинні будуватися за строгою структурою, які повинні контролюватися XSD схемами. 


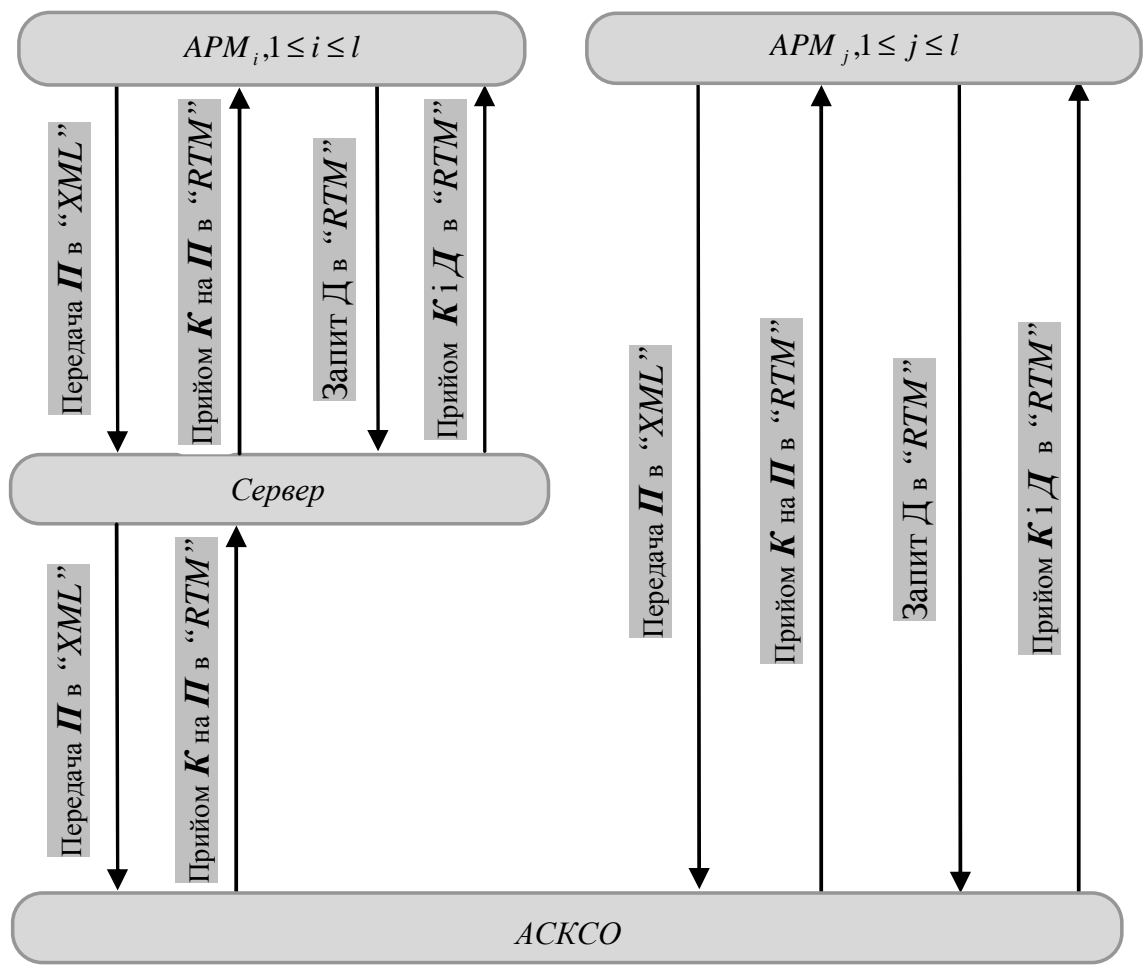

Рис. 2. Блок-схема передавання і приймання інформації для моделі складних об'єктів: $\boldsymbol{\Pi}$ - повідомлення; $\boldsymbol{K}$ - квитанція; Д - довідка

Структура XML файла, який оброблений в АCKCO:

$<$ ?xml version $=" 1.0 "$ encoding $="$ windows $-1251 "$ standalone $="$ yes"?>

$\left\langle\right.$ Nets_Petri schema $=" M \_S "$ doc_version $=" 1.0$ " doc_type $=$ "query" subtype $=" 0 ">$

$<H E A D$ messcode $="$ "nnn" from="change" password="tiger" RETFMT="XML"/>

$<$ Body $>$

// Початок

//Тіло повідомлення, яке оброблене обробником 1 або обробником 2 в АСКСО

// Кінеиь

$\langle/$ Body $>$

$</ N e t s+P e t r i>$

Структура XML файла, який оброблений сервером:

$<$ ? xml version $=" 1.0 "$ encoding $="$ windows $-1251 "$ standalone $="$ yes"? $>$

$<$ Nets_Petri schema $=" \boldsymbol{M} \_\boldsymbol{F}$ " doc_version="1.0" doc_type $=$ "query" subtype $=" 0$ " >

$<H E A D$ messcode $=" n n n n "$ from = "change" password="tiger" RETFMT="XML"/>

$\langle$ Body>

// Початок

//Тіло повідомлення, яке оброблене сервером

// Кінеиь

$\langle/$ Body $>$

$</ N e t s \_P e t r i>$

Структура XML файла, який оброблений в APMi (APMj)

$<? x m l$ version $=" 1.0 "$ encoding $="$ windows -1251 " standalone $="$ yes"?>

$<$ Nets_Petri schema $=" \boldsymbol{M} \_$Sub $-\boldsymbol{F} "$ doc_version $=" 1.0$ " doc_type $=$ "query" subtype $=" 0$ " >

$<H E A D$ messcode $=" n n n n "$ from $="$ change" password $="$ tiger" $R E T F M T=" X M L " />$

$<$ Body $>$

// Початок

//Тіло повідомлення, яке оброблене в АРМі (АРМј)

// Кінеиь

$</$ Body $>$

$</$ Nets_Petri $>$ 
У сучасних розроблених АРМах, серверах і АСКСО, як правило, RTM файли формуються 3 кодовою сторінкою Windows 1251. Можливе формування RTM файлів 3 кодовою сторінкою MS DOS 866 в APMax старих версій. Тоді в таких випадках виникає потреба в перекодуванні RTM файлів $з$ кодовою сторінкою MS DOS 866 у RTM файли з кодовою сторінкою Windows 1251.

Звичайно необроблені XML файли як на сервері, так і в АСКСО відсіваються. Пропонується створювати макети оброблених повідомлень і макети необроблених повідомлень (МНП) як на сервері, так і в АСКСО. Тоді з'являється можливість запросити необроблене повідомлення 3 МНП (сервера або АСКСО), відкорегувати його і передати знову на обробку у відповідну систему.

\section{Висновки}

1. Побудовано модель складних об'єктів із застосовуванням методу декомпозиції за ієрархічною структурою 3 трьох рівнів мереж. На 1-му рівні розміщено мережу-сценарій, яка моделює автоматизовану систему керування складними об'єктами. На 2-му рівні розміщено функцію-мережу, яка моделює сервер, на якому обробляються повідомлення, які передаються $3 l$ автоматизованих робочих місць i відповідно запрошуються інформаційні довідки із сервера. На 3-му рівні розміщено $l$ підфункцій-мереж, які моделюють $l$ автоматизованих робочих місць і $m$ підфункцій-мереж, які моделюють $m$ автоматизованих робочих місць, 3 яких передаються повідомлення в мережу-сценарій для їх обробки і відповідно запрошуються інформаційні довідки з мережі-сценарію.

2. Введено позначенння величин в XML для мереж-сценаріїв, функцій-мереж і підфункцій-мереж.

3. Розроблено структуровані XML файли вхідних даних для мереж-сценаріїв, функцій-мереж i підфункцій-мереж.

\section{Лiтература}

1. Селецький, B. C. XML i математичний апарат мереж Петрі [Текст] / В.С. Селецький // Інформаційно-керуючі системи на залізничному транспорті. - 2015. - № 6. - С. 42-45.

2. Селецький, В. С. Розширення мереж Петрі і XML [Текст] / В.С. Селецький // Інформаційно-керуючі системи на залізничному транспорті. - 2016. - № 1. - C. 62-70.

3. Reisig W. «Petri nets - an introduction» (EATCS Monographs on Theoretical Computer Science 4); Springer Verlang 1985.

4. F.Corsi and B.Castagnolo. Probablistie delay evaluation in combinational digital circuits by Petri nets// Microelectronics and Reliab., Vol. 23,No. 3, pp.541-553, 1983.
5. G.Florin, C. Franze and S. Natkin. Stochastic Petri nets: properties, aplications and tools //Microelectronics and Reliab., Vol. 31,No. 4, pp. 669-697, 1991.

6. Po-Zung Chen,Steven C. Bruell and Giarfranco Balbo.Formulating and solving optimization problems using stochastic timed Petri nets // Microelectronics and Reliab., Vol. 31,No. 4, pp.769-792, 1991.

7. Луханін, M. I. Застосування методу декомпозицій для моделювання підсистеми розформування на сортувальній станції Львів [Текст] / М.I. Луханін, В.С. Селецький // Інформаційно-керуючі системи на залізничному транспорті. - 2001. - № 4. - С. 1620.

8. Селецький, В. С. Мережі Петрі в n-вимірному просторі та їх застосування на залізничному транспорті [Текст] / В.С. Селецький // Інформаційно-керуючі системи на залізничному транспорті. - 2010. - № 4. - С. 15-19.

Селецкий В.С. Технология разработки информационного обеспечения для моделей сложных объектов. В разработке информационного обеспечения для моделей сложных объектов, построенных с помощью расширенных сетей Петри с использованием метода декомпозиций, предложен алгоритм создания структурированных XML файлов входных данных для сетей - сценариев (1-й уровень сетей), функций-сетей (2-й уровень сетей), подфункций - сетей (3-й уровень сетей) и т.д. для обеспечения достоверности обработки данных на каждом уровне.

Ключевые слова: модель, метод декомпозиции, расширенная сеть Петри, XML файлы входных данных.

Selezkyj V.S. The technology development of information support for complex object models. The paper model complex objects with different applicable decomposition is based on a hierarchical structure of three levels of networks:

- 1 - level, hosted network - scenario that simulates the automated control system of complex objects (ACSCO). In ACSCO - processed messages transmitted from the $m$ workstations $\left(A P M_{j}\right.$, where $\left.1 \leq j \leq m\right)$ and ACSCO incoming messages are processed on the server.

- 2 - level, placed function - network that simulates a server which processed messages transmitted from $l$ workstations $\left(A P M_{i}\right.$, where $\left.1 \leq i \leq l\right)$.

- 3 - level, placed:

a) sub-functions - network $s F_{i}$, where $1 \leq i \leq l$, that model $A P M_{i}$, where $1 \leq i \leq l$. In $A P M_{i}$, where $1 \leq i \leq l$ prepared the message type " $1 "$ is transmitted to 
the server $F_{1}$ and accordingly $l^{\prime}$ invited background reports from the server $F_{1}$.

b) sub-functions - network $s F_{J}$, where $1 \leq j \leq m$, that model $A P M_{j}$, where $1 \leq j \leq m$. In $A P M_{j}$, where $1 \leq j \leq m$ prepared the message type "2" transmitted in ACSCO - $S_{1}$ and accordingly m background reports are invited from ACSCO - $S_{1}$.

In developing the model for information support of complex objects proposed create structured XML input files for networks - scenarios, functions - networks and sub-functions - networks, etc.

The model for the construction of complex objects generalized dynamic table operation processes to build a shared dynamic tables functioning processes for $A P M_{i}$, where $1 \leq i \leq l$ and to $A P M_{j}$, where $1 \leq j \leq m$, a table dynamic operation of server processes and dynamic table operation processes ASKSO - $S_{1}$.

Key words: model, decomposition method, an extended Petri net, XML file input.

Рецензент доктор фіз.-мат. наук, професор М. М. Зарічний (Львівський національний університет ім. І. Франка)

Надійшла 23.09.2016 p.

Селецький В.С., к.т.н., провідний інженер віділу ІОЦ ПС, Інформачійно-обчислювальний центр Львівської залізниці, Львів, Украӥна.

Selezkyj V.S., Ph.D., senior engineer of the ICC BS, information and computing center of Lviv Railways, Lviv, Ukraine. 